(c) American Dairy Science Association, 2005.

\title{
Pregnancy Rates and Milk Production in Natural Service and Artificially Inseminated Dairy Herds in Florida and Georgia*
}

\author{
A. de Vries, ${ }^{1}$ C. Steenholdt, ${ }^{2}, \dagger$ and C. A. Risco ${ }^{2}$ \\ ${ }^{1}$ Department of Animal Sciences, and \\ ${ }^{2}$ Department of Large Animal Clinical Sciences, University of Florida, Gainesville 32611
}

\begin{abstract}
Effects of artificial insemination (AI) and natural service (NS) breeding systems on pregnancy rates (PR) by stage of lactation, season, and changes in milk production over time were examined using lactation and herd DHIA records of Holstein cows in dairy herds located in Florida and Georgia. The reported genetic profile of service sires of the herd was used to determine the percentage of cows bred to natural service bulls (\%NS). Two seasons were considered: winter (November-April) and summer (May-October) from 1995 to 2002 (16 periods). Herd-periods were assigned 1 of 3 breeding systems: AI (0 to $10 \% \mathrm{NS}$ ), mixed (11 to $89 \% \mathrm{NS}$ ) and NS (90 to $100 \%$ NS). Seventy percent of the herds used NS bulls as a component of their breeding system during the study period. The PR during winter (17.9\%) was greater than that during summer (9.0\%). During winter, PR for AI herds (17.9\%) did not differ from that for mixed (17.8\%) and NS herds (18.0\%). During summer, PR for AI herds (8.1\%) was slightly less than that for mixed $(9.3 \%)$ and NS herds $(9.8 \%)$. During winter, PR for cows at 71 to $91 \mathrm{~d}, 92$ to $112 \mathrm{~d}$, and 113 to $133 \mathrm{~d}$ in milk were $1.4 \%$ lower for mixed herds compared with $\mathrm{AI}$ and NS. Pregnancy rate for NS herds was $2.6 \%$ lower during late lactation compared with $\mathrm{AI}$ and mixed herds. During summer, PR for cows at 71 to 91 and 92 to $112 \mathrm{~d}$ in milk were 2.6 and $1.8 \%$ greater, respectively, for NS herds compared with AI. However, from 260 to $364 \mathrm{~d}$ in milk, PR for NS herds was less than that for AI and mixed herds. No significant interaction was detected between breeding system and lactation number. Rolling herd average milk production during the study period was less in the NS herds $(7180 \mathrm{~kg})$ com-
\end{abstract}

\footnotetext{
Received July 24, 2004.

Accepted October 12, 2004.

Corresponding author: Carlos Risco; e-mail: riscoc@mail.vetmed. ufl.edu.

*This research was supported by the Florida Agricultural Experiment Station and a grant from the Southeast Milk, Inc., Dairy CheckOff program, and approved for publication as Journal Series No. R-10336.

$\dagger$ Current address: High Plains Veterinarians Outlet, Clovis, NM 88101.
}

pared with AI ( $8513 \mathrm{~kg})$ and mixed herds $(8176 \mathrm{~kg})$, but the annual change in milk production was not different among breeding systems. The results indicated that use of NS bulls did not result in meaningful disadvantages in terms of $\mathrm{PR}$ and changes in milk production over time.

(Key words: pregnancy rate, milk production, natural service, artificial insemination)

Abbreviation key: DRMS = Dairy Records Management Systems, NS = natural service breeding system, $\% \mathbf{N S}=$ percentage natural service breedings, $\mathbf{P R}=$ pregnancy rate, $\mathbf{V W P}=$ voluntary waiting period.

\section{INTRODUCTION}

Selection of the type of breeding system used in a dairy herd should be based on the ability of that system to maximize reproductive performance. A common measure of reproductive performance is pregnancy rate (PR), defined as the product of estrus detection and conception rate (Ferguson and Galligan, 1999). Pregnancy rate represents the proportion of cows that become pregnant each estrous cycle and it determines days open after the voluntary waiting period (VWP). As PR increases, days open are reduced, thereby increasing the amount of milk produced per day of herd lifetime and reducing the number of cows culled for reproductive failure (Risco et al., 1998).

The economic value of a marginal improvement in PR is greater at lower levels of PR. Pecsok et al. (1994) changed heat detection from 0.7 to 0.6 (at 70\% conception rate). This is a change in PR from 0.49 to 0.42 and reported a loss of $\$ 6.00$. A 0.01 increase in PR about halfway (0.45 to 0.46 ) is $\$ 0.86$ per cow-yr $(\$ 6.00 / 7)$. In addition, they changed heat detection from 0.3 to 0.2 (at 50\% conception rate). This is a change in PR from 0.15 to 0.10 resulting in a loss of $\$ 83.00$. A 0.01 increase in $\mathrm{PR}$ about halfway (0.12 to 0.13 ) is $\$ 16.00$ per cowyr (\$83.00/5). Risco et al. (1998) reported no increase in net revenue beyond a PR of 35\%. Plaizier et al. (1998) reported similar diminishing returns at greater PR, suggesting that changes in the type of breeding systems in dairy herds with a PR above $25 \%$ may not result in 
an economic advantage. In the southeast region of the US, however, overall herd PR is much less than $25 \%$. In Florida and Georgia, average days open have increased from approximately $130 \mathrm{~d}$ in 1983 to more than $180 \mathrm{~d}$ in 1999 (Washburn et al., 2002). This indicates a decrease in average PR from approximately 23 to $15 \%$ $[\mathrm{PR}=21$ / (days open - VWP + 11); VanRaden et al., 2004]. Consequently, the low PR indicates that even small differences in PR resulting from different breeding systems can be economically important.

Washburn et al. (2002) found that both estrus detection and conception rates have decreased. To overcome problems associated with estrus detection, many dairies use natural service (NS) bulls, either immediately after the VWP, or after an unsuccessful AI period. The perception is that PR improves when NS is used because more cows are detected in estrus and serviced. Reported use of NS as a component of the breeding system in dairy herds varied from 55 to $74 \%$ (NAHMS, 2002; Smith et al., 2004).

Several studies have compared reproductive performance between AI and NS breeding systems. Pregnancy rates obtained from dairy herd records of cows bred by AI or NS were not different (Williamson et al., 1978; Niles et al., 2002), but PR from NS was more variable in NS herds (Williamson et al., 1978). Using DHI herd summary information, actual calving interval was shorter in herds that used NS bulls (Smith et al., 2004). However, overall reproductive efficiency as measured by the percentage of cows in milk and herd milk production was greater for AI herds and declined as the percentage of NS increased. Greater milk production obtained in AI herds is related to superior genetics of raised replacements (Cassell et al., 2002).

A high PR immediately after the VWP resulted in more cows becoming pregnant earlier in lactation, thus maximizing farm income (Risco et al., 1998). However, studies on the effect of breeding system (AI- or NSbased) on PR by stage of lactation are lacking. Secondly, effect of summer heat stress on PR resulting from different breeding systems has not been evaluated for the southeast region. Finally, we found no documentation of the effect of breeding system on change in milk production over time. Our objectives were to determine the effect of breeding systems based on AI, NS, or a combination, on PR by stage of lactation, season, and on changes in milk production over time.

\section{MATERIALS AND METHODS}

Our time span of interest (November 1, 1994 to October 31,2002 ) was determined by 2 available data sets. Two seasons of 6 mo each were considered: winter (November-April) and summer (May-October). Data were available for 8 consecutive years of 2 seasons each (16 periods). The last month of each season determined the year. For example, the first season (November 1994 through April 1995) is referred to as the winter of 1995.

\section{Data Set 1: Lactation Records}

Lactation records of all Holstein cows in herds located in Florida and Georgia that were tested by DHIA were obtained from Dairy Records Management Systems (DRMS) in Raleigh, NC. Each record started with a calving date. Records with calving dates between February 4, 1995 and October 31, 2002, were used because these records could contribute days open in the PR calculations for the time span of interest (November 1, 1994 to October 31, 2002). A lactation record was considered completed when a subsequent calving date was recorded for the same cow. Otherwise, the record was considered not completed.

For all records, we estimated the date of conception (if any). Conception dates for completed records were calculated by adding the reported days open to the calving date that started the record. However, if the resulting parturition length was less than $230 \mathrm{~d}$ or more than $300 \mathrm{~d}$, then this conception date was calculated as the next calving date minus $280 \mathrm{~d}$. Using the calculated conception date, days open for the completed lactation record were calculated as the number of days between the calving date and the conception date. Conception dates that resulted in abortion could not be determined. Thus, only the conception date that resulted in a subsequent calving date was used. All completed records resulted in a pregnancy.

Days open for the records that were not completed by October 31, 2002 were calculated as follows. If a cow had a reported due date, then the conception date was calculated as $280 \mathrm{~d}$ before the due date. If that conception date was on or before October 31, 2002, then days open was calculated as the number of days between calving date and conception date. Otherwise, days open was calculated as the number of days between the calving date and October 31, 2002, and the record was censored. If a cow did not have a reported due date, but was reported pregnant, her last breeding date was used as the conception date. Otherwise, a cow was assumed not to have a conception date and days open was censored at her last known event date or October 31, 2002, whichever was earlier. For these cows, the last known event date was the last known calving date, breeding date, or test date. Each conception date was assumed the start of a pregnancy.

\section{Data Set 2: Herd Records}

Herd Summary Report DHI-202 records with DHIA test days between 1995 and 2003 were obtained for 
all Holstein herds located in Florida and Georgia from DRMS. The most recent test day data in each record were used. We used the reported genetic profile of service sires (3 categories: percentage of herd bred to proven AI sires, AI young sires, or all other sires) to determine the percentage bred to all other sires, assumed to be from natural service bulls (\%NS), in each of the 16 periods of interest. The genetic profile of the service sires is calculated by DRMS from the service sires of the most current breedings of all cows in the herd on test day, provided the breeding was in the current lactation (John Clay, personal communication, 2004). The genetic profile is therefore a rolling average of approximately 9 mo.

We calculated the average \%NS on the test days in June through August to determine the breeding system during the preceding winter. Similarly, we calculated the average \%NS on test days in December through February to determine the breeding system during the preceding summer. The average \%NS then was used to classify each herd in each period in 1 of 3 breeding systems: AI ( 0 to $10 \% \mathrm{NS}$ ), mixed (11 to $89 \% \mathrm{NS}$ ), or NS (90 to $100 \%$ NS).

To test the association of breeding system and changes in milk production over time, we calculated the average rolling milk production in October through December per year for each herd. These test day yields were averaged because some herds did not have a test day yield in every month. However, at least one test day yield during October through December was often available. Calculated rolling herd milk production was assumed to be representative of the average milk production during each year, defined as starting in November of the previous year. Herd and lactation records from both data sets were merged, resulting in 729,824 lactation records in 579 herds.

\section{Statistical Analyses}

Data editing and statistical analyses were performed using SAS version 8.2 (SAS Institute, Inc., Cary, NC). Main results of interest were the effect of season, breeding system, and their interaction on PR and the association between breeding system and the change in milk production over time.

Separate PR were calculated per herd per period in multiples of $21 \mathrm{~d}$ for 7 stages of lactation: 71 to 91,92 to 112,113 to 133,134 to 196,197 to 259,260 to 364 , and 71 to 364 DIM. In addition, PR from 71 to $364 \mathrm{~d}$ were calculated separately for first and greater lactations. For each stage, we calculated the cumulative number of days at risk for pregnancy and the number of new conceptions. For example, to calculate the PR during 197 to $259 \mathrm{~d}$ after calving during summer of
1997, we counted each cow's total days at risk from 197 to $259 \mathrm{~d}$ in lactation between May 1, 1997 and October 31,1997 . The cumulative number of days at risk divided by 21 equals the cumulative number of cows eligible for conception within that stage of lactation during that period. We also counted the total number of new conceptions during that period. The PR in period $i$ for herd $j$ was calculated as:

$$
\begin{gathered}
\mathrm{PR}_{\mathrm{ij}}=(\text { cumulative number of conceptions })_{\mathrm{ij}} / \\
(\text { cumulative number of eligible cows })_{\mathrm{ij}}
\end{gathered}
$$

To limit the effect of unreliable PR, observations for herd periods with less than 210 cumulative days at risk for pregnancy were excluded from the analyses. The PR during 71 to 364 DIM was estimated using the Actuarial method with 21-d steps in procedure LIFEREG. The dependent variable was days at risk during the lactation. Every lactation was one record. Lactation records were stratified by breeding system on the first day after the VWP. This survival analysis method did not consider the effect of season, herd, and possible change of breeding system between periods on the PR.

A first mixed model (procedure MIXED) was used to analyze the effect of year and season on \%NS. Year and season were included as fixed effects and herd as a random effect. The \%NS per period were treated as repeated measures within herd. This specification can appropriately handle missing and unbalanced data (Littell et al., 1996). A first-order autoregressive covariance structure between the repeated records within herds was specified, because its Akaike information criterion suggested a better fit to the data than the default (no covariance), compound symmetry, or unstructured covariance structures (Littell et al., 1998). The firstorder autoregressive covariance structure and a random herd effect were used for all subsequent mixed models. Significance was declared at $P<0.05$.

A second mixed model was used to analyze the effect of year, season, breeding system and the season $\times$ breeding system interaction on PR. All independent variables were fixed. Pregnancy rates per period were treated as repeated measures within herd. The Satterthwaite approximation for the denominator degrees of freedom was used to obtain the degrees of freedom for the contrasts of breeding system and season (Littell et al., 1996). Differences between least squares means were compared using the Tukey option to adjust for multiple comparisons.

To estimate the interaction between breeding system and lactation number, PR for 71 to $374 \mathrm{~d}$ were calculated separately for first and greater lactations, and then combined in one data set. A third mixed model was specified as before, but independent fixed effects 


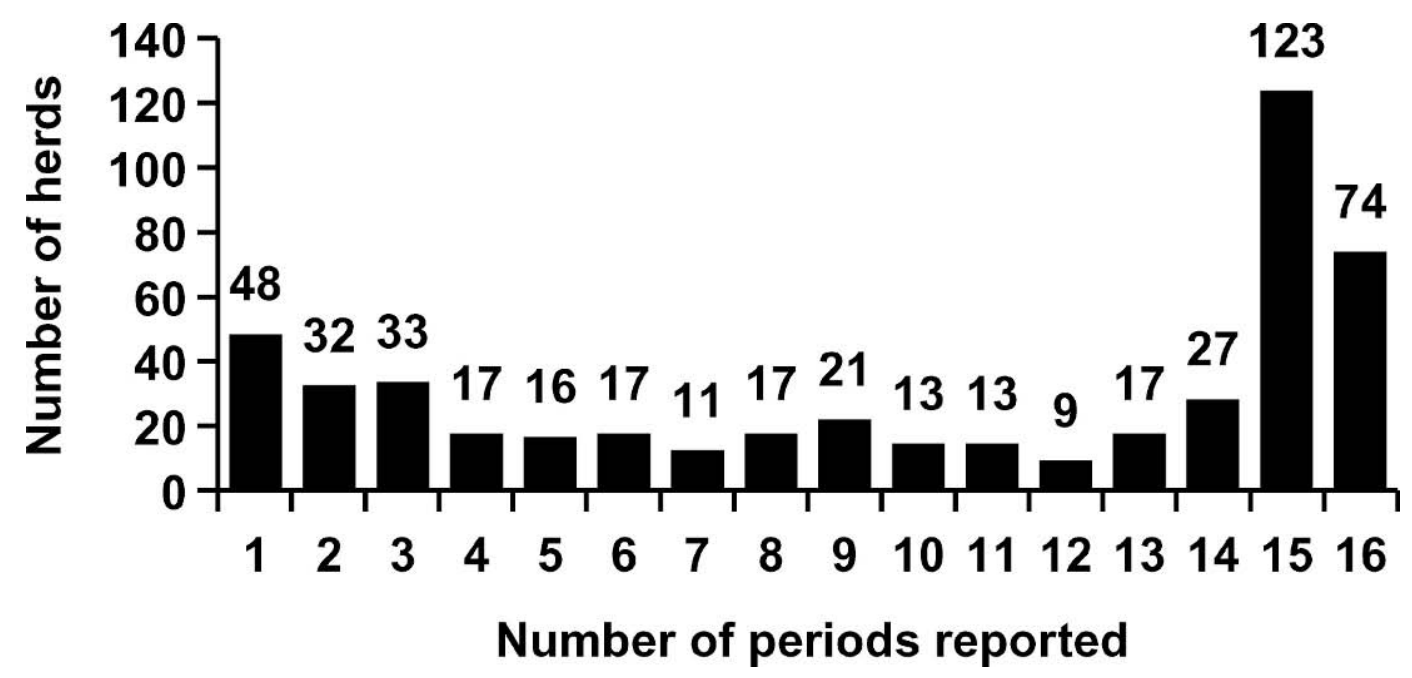

Figure 1. Number of herds reporting at least one period for the calculation of pregnancy rates between 71 and 364 DIM. A total of 488 herds reported.

were year, season, breeding system, and lactation number, and all interactions of the latter 3 variables.

A fourth mixed model was used to obtain regression equations of the effect of \% NS on PR for both seasons. Pregnancy rates per period were treated as repeated measures within herd.

Also of interest was whether the breeding system had an effect on the change in milk production over time. Included in this analysis were herds that did not change breeding system during any of the periods for which they reported PR. A fifth mixed model with rolling herd milk production as the dependent variable had year and breeding system as fixed effects. The rolling herd milk production per year was treated as repeated measures within herd. This model estimated the level of rolling herd milk production per breeding system. Other options were the same as in the second mixed model specification.

A sixth mixed model was used with annual change in rolling herd milk production as the dependent variable and year, breeding system, the previous year's rolling herd milk production, and the interaction of the latter 2 variables. Breeding system and year were fixed effects, whereas the previous year's rolling herd milk production was a covariate. Change in rolling herd milk production per year was treated as repeated measures within herd. Again other options were the same as in the second mixed model specification. Herds were included in this analysis if they did not change breeding system during any of the periods for which they reported PR and had at least 2 consecutive years of rolling herd milk production.

\section{RESULTS}

The final data set included 4872 herd-period observations in 488 herds. The average number of periods with complete observations per herd was $4872 / 488=10.0$. Forty-eight herds reported only during one period, whereas 74 herds reported during all 16 periods (Figure 1). All these herd-periods contributed to the calculation of PR between 71 and 364 DIM. Pregnancy rates that were calculated for a smaller stage of lactation (e.g., 71 to $91 \mathrm{~d}$ ) often had fewer herd-periods (and herds) included in the analysis, because fewer herd-periods had at least 210 cumulative days at risk for pregnancy.

\section{Breeding System}

Figure 2 shows the distribution of the percentage of NS during 4872 herd-periods. Eight percentage of all periods were $0 \% \mathrm{NS}$ and $25 \%$ of all periods were $100 \%$ NS. Table 1 shows that of 4872 periods, 1458 periods were reported by 233 herds as breeding system AI. A minimum of 1441 herd-periods was reported for breeding system NS with 216 herds reporting at least one such period. Of the 488 herds, 231 herds (47.3\%) reported only 1 type of breeding system: AI was reported by 54 herds (11.1\%), mixed by 79 herds (16.2\%), and NS by 98 herds (20.1\%). These 231 herds reported anywhere from 1 to 16 periods. One hundred thirty-nine herds $(28.5 \%)$ reported both $\mathrm{AI}$ and mixed breeding systems, but not NS. Only 2 herds reported AI and NS, but not the mixed breeding system. Seventy-eight herds (16.0\%) reported both mixed and NS breeding systems, 


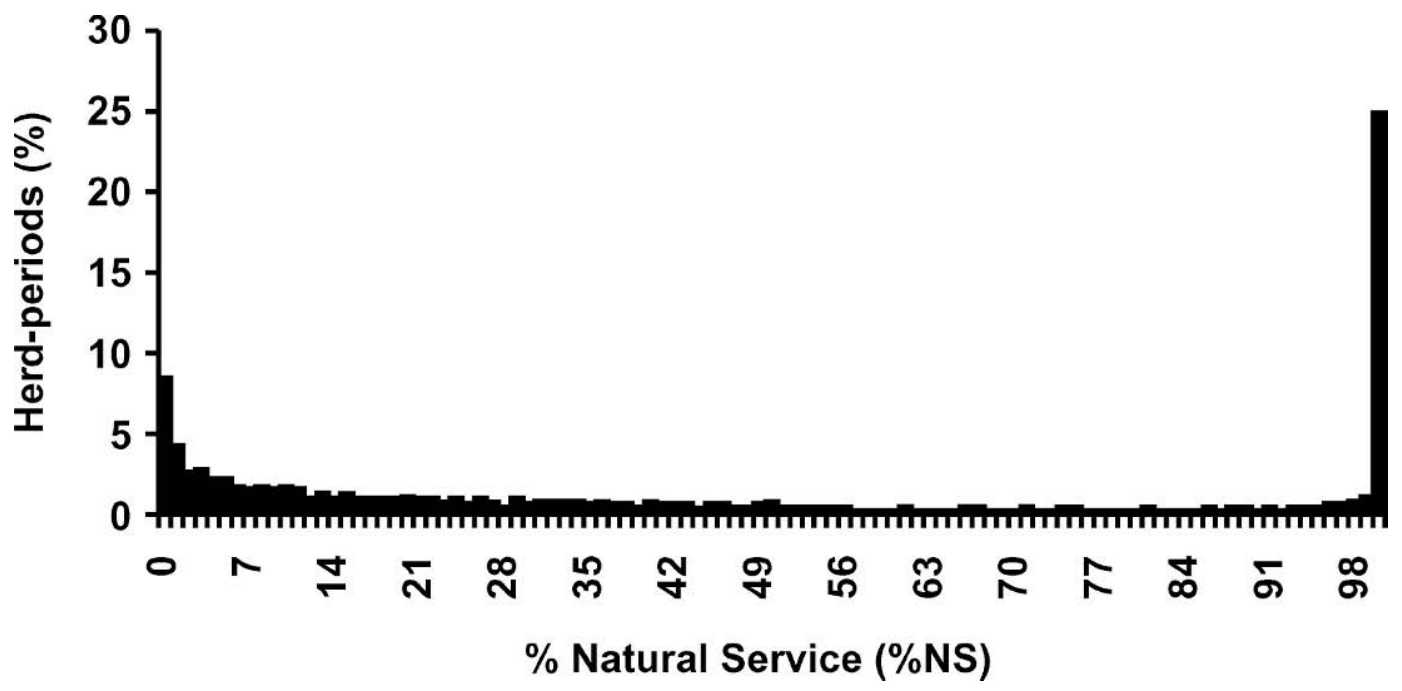

Figure 2. Percentage natural service breedings in 4872 herd-period combinations between 1995 and 2002 in 488 herds. Each period is 6 mo.

but not AI. The remaining 38 herds (7.8\%) reported all 3 breeding systems.

Results from the first mixed model showed that the average \%NS during winter $(48 \%)$ was slightly greater $(P<0.01)$. than during summer $(47.2 \%)$. Furthermore, there was no significant year effect on $\% \mathrm{NS}$ during the $8 \mathrm{yr}$ of this study. Compared with the previous herdperiod, $36.1 \%$ of herd-periods had a decreased $\% \mathrm{NS}$ and $36.7 \%$ had an increased \%NS. The decrease was on average $11.3 \% \mathrm{NS}$ and the increase was on average $11.6 \% \mathrm{NS}$. The remainder of herd-periods $(27.2 \%)$ had the same $\% \mathrm{NS}$ as the previous period.

\section{Pregnancy Rates}

Nonparametric estimates of PR by 21-d intervals for the 3 breeding systems using survival analysis are shown in Figure 3. Of the 536,681 lactation records, $121,993(22.7 \%)$ did not have a date of conception and were censored. The Logrank and Wilcoxon tests showed differences $(P=0.003)$ among the breeding systems.

Table 1. Number of herd-periods and number of herds reporting 1 of 3 breeding systems.

\begin{tabular}{lllll}
\hline $\begin{array}{l}\text { Breeding } \\
\text { system }^{1}\end{array}$ & \multicolumn{2}{c}{ Herd-periods } & \multicolumn{2}{c}{ Herds reporting } \\
\hline AI & 1458 & $(29.9 \%)$ & 233 & $(47.7 \%)^{2}$ \\
Mixed & 1973 & $(40.5 \%)$ & 344 & $(70.5 \%)$ \\
NS & 1441 & $(29.6 \%)$ & 216 & $(44.3 \%)$ \\
\hline
\end{tabular}

${ }^{1}$ Breeding systems: AI ( 0 to $10 \%$ NS), mixed (11 to $89 \%$ NS), or NS (90 to $100 \% \mathrm{NS}$ )

${ }^{2}$ Percentage of herds reporting the breeding system in at least one period of 488 herds.
Noticeable differences in PR were evident after approximately 220 DIM, with the NS breeding system having the lowest PR. However, these PR were not adjusted for year, season, herd, and possible changes in breeding system during lactation.

Results from the second mixed model for PR calculated for 71 to 364 DIM throughout the 8-yr study period showed effects of year, season, and the breeding system

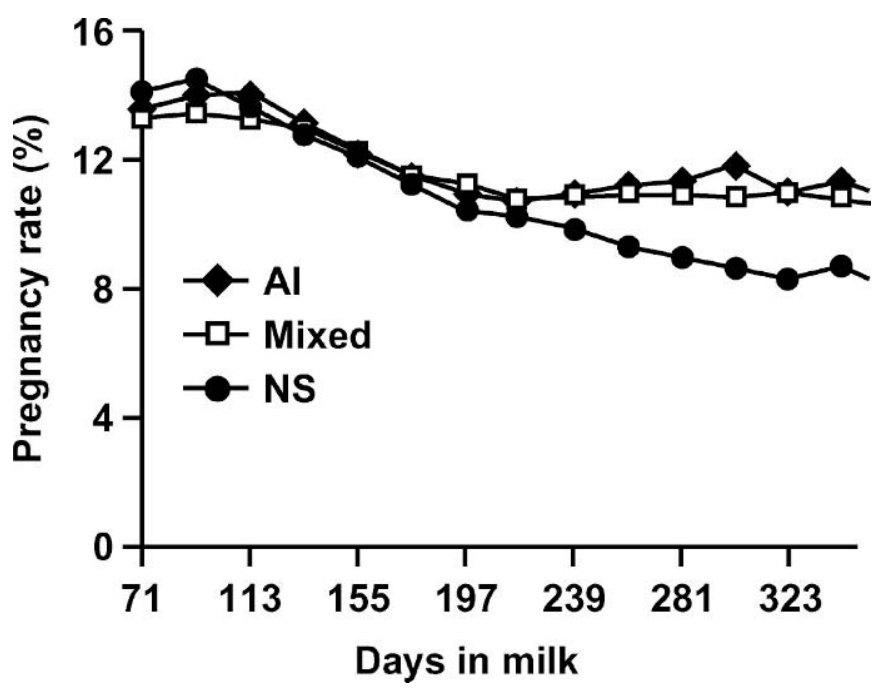

Figure 3. Nonparametric estimates of pregnancy rates per 21-d intervals for 3 breeding systems AI (0 to 10\% NS), mixed (11 to $89 \%$ NS), and NS (90 to $100 \%$ NS). Breeding system was assigned on d 71. The standard error increased approximately linearly from $0.10 \%$ early in lactation to $0.25 \%$ at the end of the lactation. These estimates have not been adjusted for the effects of year, season, and herd. $\% \mathrm{NS}=$ Percentage natural service breedings. 


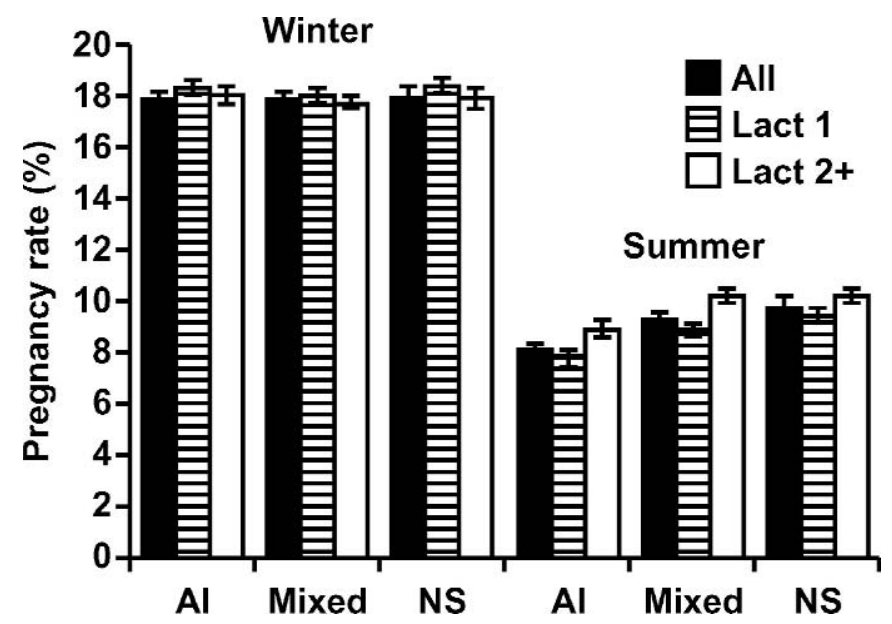

Figure 4. Least squares means \pm SEM of pregnancy rates $(\%)$ for 71 to 364 DIM for 3 breeding systems, AI (0 to 10\% NS), mixed (11 to $89 \% \mathrm{NS}$ ), and NS (90 to $100 \% \mathrm{NS}$ ), during winter and summer. Pregnancy rates are estimated for lactation numbers $1, \geq 2$, and all lactations. $\% \mathrm{NS}=$ Percentage natural service breedings.

$\times$ season interaction $(P<0.001)$ and breeding system $(P<0.05)$. Pregnancy rates during winter $(17.9 \%)$ were greater $(P<0.001)$ than those during summer $(9.0 \%)$. In the winter, $\mathrm{PR}$ for $\mathrm{AI}$ herds (17.9\%) was no different than that for mixed (17.8\%) and NS herds (18.0\%) (Figure 4). In the summer, PR for AI herds (8.1\%) was lower than that for mixed $(9.3 \% ; P=0.001)$ and NS herds $(9.8 \% ; P<0.001)$. The PR for mixed and NS herds were not significantly different.

During winter, PR (71 to 364 DIM) for first-lactation cows was $0.4 \%$ greater $(P<0.05)$ than that in older cows. During summer, older cows had a $1.1 \%$ greater $(P<0.001)$ PR than first-lactation cows. Although the interaction between season and lactation number was significant $(P<0.001)$, no significant interaction was detected between breeding system and lactation number.
Table 2 shows the PR for various stages of lactation. During winter, PR for stages 71 to $91 \mathrm{~d}, 92$ to $112 \mathrm{~d}$, and 113 to $133 \mathrm{~d}$ in lactation were approximately $1.4 \%$ less in the mixed herds than in the NS herds. The PR of the AI herds did not differ from that in the mixed or NS herds. Pregnancy rate for NS herds was approximately $2.6 \%$ less $(P<0.001)$ during late lactation $(260$ to 364 DIM) compared with AI and mixed herds. (Pregnancy rates for other stages of lactation did not differ among treatments). During summer, PR during 71 to 91 and 92 to 112 DIM were $2.6 \%(P<0.001)$ and $1.8 \%$ $(P=0.01)$ greater, respectively, for NS herds than for AI herds. However, from 260 to 364 DIM, PR for NS herds was $1.8 \%$ less $(P<0.001)$ than for mixed herds. The PR for the other stages did not differ among treatments during summer.

Regression of PR on \%NS supported the trends illustrated in Table 2 and Figure 4. For PR from 71 to 364 DIM, the fourth mixed model showed no significant effect of $\%$ NS during winter $(\mathrm{PR}=17.7 \%)$. During summer, both $\% \mathrm{NS}$ and $(\% \mathrm{NS})^{2}$ were significant and the regression equation was $\mathrm{PR}=7.9+6.10 \times 10^{-2} \times \% \mathrm{NS}$ $-3.92 \times 10^{-4} \times(\% \mathrm{NS})^{2}$. The maximum PR $(10.2 \%)$ with this model was obtained when \%NS was 78. Regression equations for later stages of lactation (133 to 364 DIM) showed the greatest PR during winter $(8.4 \%)$ when $\% \mathrm{NS}$ was $45\left(\mathrm{PR}=17.5+3.91 \times 10^{-2} \times \% \mathrm{NS}-4.38 \times\right.$ $\left.10^{-4} \times[\% \mathrm{NS}]^{2}\right)$ and during summer when $\% \mathrm{NS}$ was 60 $\left(\mathrm{PR}=8.1+5.87 \times 10^{-2} \times \% \mathrm{NS}-4.89 \times 10^{-4} \times[\% \mathrm{NS}]^{2}\right)$. Thus, during the later stages of lactation, the maximum PR was estimated for \%NS classified as the mixed breeding system.

\section{Milk Production}

For the 231 herds that did not change breeding systems during their reported periods, there were 526 annual records in 132 herds that included an annual

Table 2. Pregnancy rates (\%; least squares \pm SEM) for various stages of lactation for the 3 breeding systems during winter and summer. ${ }^{1}$

\begin{tabular}{|c|c|c|c|c|c|c|}
\hline \multirow{2}{*}{$\begin{array}{l}\text { Stage of } \\
\text { lactation }\end{array}$} & \multicolumn{3}{|c|}{ Winter } & \multicolumn{3}{|c|}{ Summer } \\
\hline & AI & Mixed & NS & AI & Mixed & NS \\
\hline 71 to 91 & $17.7 \pm 0.39^{\mathrm{ab}}$ & $16.7 \pm 0.34^{b}$ & $18.2 \pm 0.41^{\mathrm{a}}$ & $7.7 \pm 0.39^{b}$ & $9.2 \pm 0.33^{\mathrm{a}}$ & $10.3 \pm 0.40^{\circ}$ \\
\hline 92 to 112 & $18.8 \pm 0.40^{\mathrm{ab}}$ & $17.6 \pm 0.34^{\mathrm{b}}$ & $19.0 \pm 0.42^{\mathrm{a}}$ & $8.3 \pm 0.39^{b}$ & $9.5 \pm 0.33^{\mathrm{ab}}$ & $10.1 \pm 0.40^{\circ}$ \\
\hline 113 to 133 & $18.6 \pm 0.39^{\mathrm{ab}}$ & $17.6 \pm 0.33^{b}$ & $19.0 \pm 0.41^{\mathrm{a}}$ & $8.4 \pm 0.37^{\mathrm{a}}$ & $9.2 \pm 0.31^{\mathrm{a}}$ & $9.6 \pm 0.39^{a}$ \\
\hline 134 to 196 & $18.4 \pm 0.34^{\mathrm{a}}$ & $17.8 \pm 0.30^{\mathrm{a}}$ & $17.2 \pm 0.36^{\mathrm{a}}$ & $8.2 \pm 0.32^{\mathrm{a}}$ & $9.1 \pm 0.28^{\mathrm{a}}$ & $9.3 \pm 0.34^{\mathrm{a}}$ \\
\hline 197 to 259 & $16.6 \pm 0.36^{\mathrm{a}}$ & $17.0 \pm 0.31^{\mathrm{a}}$ & $15.8 \pm 0.37^{\mathrm{a}}$ & $8.3 \pm 0.33^{\mathrm{a}}$ & $9.0 \pm 0.29^{\mathrm{a}}$ & $8.4 \pm 0.36^{\mathrm{a}}$ \\
\hline 260 to 364 & $17.5 \pm 0.41^{\mathrm{a}}$ & $17.6 \pm 0.36^{\mathrm{a}}$ & $14.9 \pm 0.43^{b}$ & $8.9 \pm 0.39^{\mathrm{ab}}$ & $9.7 \pm 0.34^{\mathrm{a}}$ & $7.9 \pm 0.42^{\mathrm{b}}$ \\
\hline
\end{tabular}

${ }^{\mathrm{a}, \mathrm{b}}$ Least squares means within stage of lactation and season having a different superscript letter differ $(P<0.05)$.

${ }^{1}$ Breeding systems: AI (0 to $\left.10 \% \mathrm{NS}\right)$, mixed (11 to $\left.89 \% \mathrm{NS}\right)$, NS (90 to $\left.100 \% \mathrm{NS}\right)$. Seasons: Winter $=$ November-April, Summer = May-October.

${ }^{2}$ Stage of lactation, e.g., $71-91$ is the pregnancy rate from 71 to 91 DIM. 
Table 3. Least squares means \pm SEM of rolling herd milk production and change in rolling herd milk production (1996-2002) for 3 breeding systems. ${ }^{1}$

\begin{tabular}{|c|c|c|c|c|}
\hline $\begin{array}{l}\text { Breeding } \\
\text { system }\end{array}$ & Herds & Annual records & Milk production & Change in milk ${ }^{2}$ \\
\hline & \multicolumn{2}{|c|}{$\longrightarrow$ No. $(\%) \longrightarrow$} & \multicolumn{2}{|c|}{$\longrightarrow \mathrm{kg} / \mathrm{cow}$ per yr } \\
\hline AI & $37(28.0 \%)$ & $145(27.6 \%)$ & $8513 \pm 177^{\mathrm{a}}$ & $100 \pm 41^{\mathrm{a}}$ \\
\hline Mixed & $35(26.5 \%)$ & $129(24.5 \%)$ & $8176 \pm 181^{\mathrm{a}}$ & $33 \pm 41^{\mathrm{a}}$ \\
\hline NS & $60(45.5 \%)$ & $252(47.9 \%)$ & $7180 \pm 135^{\mathrm{b}}$ & $-22 \pm 32^{\mathrm{a}}$ \\
\hline
\end{tabular}

change in rolling herd milk production compared with the previous year (Table 3). Almost $50 \%$ of the records and herds contained the NS breeding system. Both year and breeding system were significant in the fifth mixed model. Average rolling herd milk production per year during 1996 to 2002 was less $(P<0.001)$ in the NS herds $(7180 \mathrm{~kg})$ than in the AI $(8513 \mathrm{~kg})$ and mixed herds $(8176 \mathrm{~kg})$. The lower milk production in the NS herds compared with the AI and mixed herds is also evident in Figure 5, which shows the average rolling herd milk production from 1996 to 2002 in herds for which a change in milk production was calculated. The increase in rolling herd milk production was the greatest in AI herds and negative in NS herds, but the differences were not significant.

\section{DISCUSSION}

The breeding system for each herd-period in our study was determined from the genetic profile of service

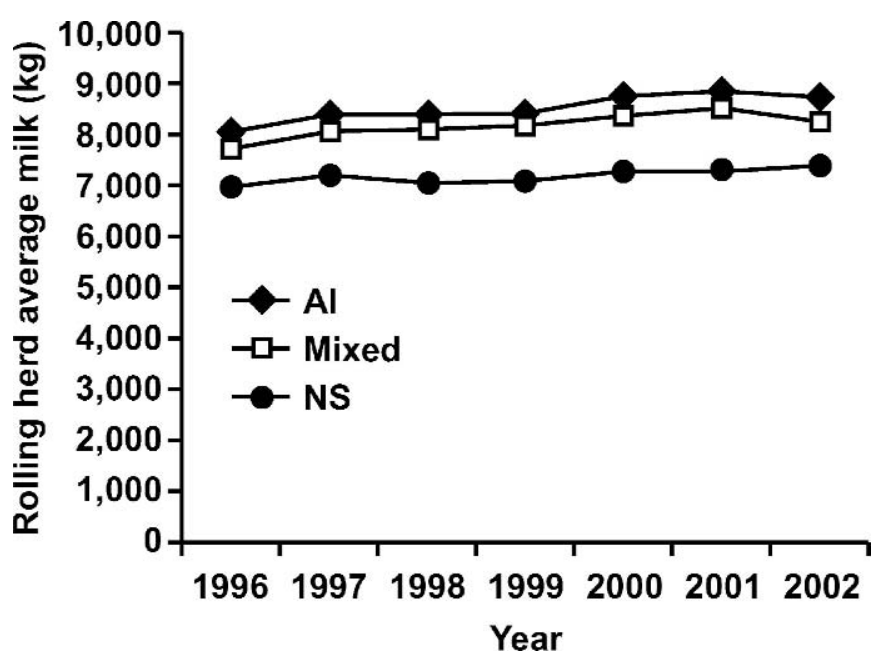

Figure 5. Least squares means of rolling herd average milk production (kg) from 1996 to 2002 for the breeding systems AI (0 to $10 \%$ NS), mixed (11 to $89 \%$ NS), and NS (90 to $100 \%$ NS) in 132 herds that did not change their breeding system. Average SEM for AI, mixed, and NS herds were 206, 209, and $155 \mathrm{~kg}$, respectively. $\% \mathrm{NS}=$ Percentage natural service breedings. sires because it was not clear from the lactation records when a cow was entered with a bull or if she as bred by AI. If these data were available for individual cows, differences in PR between AI and NS bred cows might be more profound, especially in herds that used a combination of both systems.

In our study, $70.1 \%$ of herds used the mixed or NS breeding system. Using similar criteria to assign cows to a breeding system, a study conducted from 1999 to 2002 found that $74 \%$ of dairy herds used NS bulls (Smith et al., 2004). The 2002 National Animal Health Monitoring System indicated that 54.9\% of dairy herds used NS as a component of their breeding system (NAHMS, 2002). These findings suggest that NS bulls continue to be a popular component of the breeding system in many dairy herds.

More than half of the herds changed breeding systems during the $8 \mathrm{yr}$ of the study. The classification of AI or mixed breeding systems, and to a lesser extent the NS breeding system, based on the \%NS is somewhat arbitrary (Figure 2). Different classifications produced slightly different results, but the results from regressions of PR on \%NS agreed in general with those for the breeding systems (Table 2). The mixed models did not account specifically for changes in breeding systems among periods within the same herds.

Our study showed that PR during winter in Florida and Georgia were twice as great as PR during summer. Our results agree with those of Oseni et al. (2003) who showed that days open increased during summer in most US states, including Florida and Georgia. Heat stress affects AI programs by reducing the duration of estrus and conception rate (Badinga et al., 1985). During periods of heat stress, NS bulls may experience reduced libido and sperm motility, and an increase in the number of abnormal sperm (Ott, 1986). In contrast, no clear interaction of season $\times$ breeding system on PR was evident in our study. During winter, herds with the mixed breeding system had slightly lower PR during early lactation (Table 2), but AI and NS herds had similar results. During summer, NS herds had slightly 
greater PR during early lactation. The regression equations for cows in later lactation showed the greatest $\mathrm{PR}$ for \%NS that are classified as the mixed breeding system, which is in agreement with results in Table 2. Niles et al. (2002) reported reduced PR during summer in California herds. However, they found no difference between the AI and NS breeding systems. Presumably, most herds evaluated in the present study used heat stress management practices (shade, fans, evaporative cooling, etc.). Consequently, changes in bull semen quality may have been less severe in the present study.

In general, PR was not different from 134 to 259 DIM. This is a time when some herds with a mixed breeding system expose open cows to clean up bulls after failure to achieve pregnancy by AI during earlier lactation. The results indicate that use of clean up bulls during late lactation does not reduce PR compared with sole use of AI. Our results confirm other observations (Niles et al., 2002) in which no difference in $\mathrm{PR}$ were reported between cows exposed to AI only and those exposed to clean up bulls after failure to achieve pregnancy by AI. In the present study, however, PR calculated after 260 DIM was less for NS herds during both winter and summer. These late-lactation cows may represent a subfertile group. Nonoptimal management that affects semen quality or mounting and breeding ability of NS bulls may reduce the ability of NS bulls to impregnate these cows. Indeed, if cows that remain open for a prolonged period after calving represent a subfertile group, insemination with better quality semen through AI could improve PR.

Pregnancy rates calculated during summer in our study might be less than those obtained in practice. Some dairy producers in Florida probably do not inseminate cows during part of the summer (Washburn et al., 2002). Those cows are eligible to get pregnant, but because they are not inseminated, their data should be excluded from the PR calculations. In our study, all cows open after the 70-d VWP were considered eligible for breeding and thus contributed days open to the PR calculations. No information was available to discern whether cows were eligible in actual practice or not. The VWP reported on the DHIA Herd Summary Report 202 often did not agree with the observed days to first service and was therefore ignored.

Pregnancy rates are calculated from observations representing days to conception or days to censoring (if the cow was not pregnant, the day of censoring was the last known date of calving, breeding, or milk test, or October 31, 2002, whichever was earlier). Twenty-three percent of all lactation records did not have a conception date and therefore were censored. Those cows were either culled or did not conceive by the end of the study period (October 31, 2002), or the herd was no longer tested by DHIA. Time-to-event observations are best analyzed by survival analysis (Dohoo et al., 2003). Pregnancy rates are then equal to the average hazard in 21-d periods. Furthermore, breeding system and season are time-dependent variables, because they may change during the time a cow is eligible to become pregnant. We initially attempted to estimate the effect of breeding system on days to conception with herd as a random effect by using the Survival Kit (Ducrocq and Sölkner, 1994) on lactation records. However, that model failed to converge and no reliable results could be obtained. The mixed model approach applied in our study assumed constant PR for each herd and period. Separate PR was calculated per period, and this approach could handle the time-dependent variables, breeding system and season, which could only change between periods. The model correctly accounted for repeated measures clustered within herd, and fitted herd as a random effect. A disadvantage may be that the number of cows that are included in the PR calculation per herd-period is ignored.

Herds using the NS breeding system had a lower rolling herd milk production than the mixed and AI herds. Lower milk production is consistent with other results (Smith et al., 2004). Cassell et al. (2002) reported that cows sired by proven AI sires produced 1400 $\mathrm{kg}$ more herd lifetime actual milk and were $\$ 148$ more profitable when compared with daughters of nonAI sires. However, it is not clear if the lesser milk production in the NS herds in the present study is the result of a reduced genetic gain in cows that might have been sired by NS bulls. Survey data indicate that many herds in Florida and Georgia purchase replacement heifers, possibly sired by AI, and do not raise their heifer calves as replacements (de Vries et al., 2003). This may explain why the average annual changes in rolling herd milk production were not different among breeding systems in our study.

In conclusion, NS bulls are an important component of the breeding systems in the majority of dairy herds in Florida and Georgia. Pregnancy rates during winter were twice as high as those during summer, but the use of NS bulls as a component of the breeding system did not result in different PR compared with herds that use primarily AI. Although milk production was less in the NS herds, the use of NS bulls did not necessarily limit increases in herd milk production over the study period. Whether the predominant use of herd replacements sired by NS bulls is detrimental to increases in milk production overtime beyond the $7 \mathrm{yr}$ evaluated in the present study warrants further investigation.

\section{ACKNOWLEDGMENTS}

We thank John Clay and Crystal Vierhout of Dairy Records Management Systems, Raleigh, NC, and Dan 
Webb of Southeast DHIA, Gainesville, FL, for kindly providing the data used in this study. Furthermore, we thank the dairy producers of Southeast Milk, Inc., Belleview, FL, for their financial support of this study.

\section{REFERENCES}

Badinga, L., R. J. Collier, W. W. Thatcher, and C. J. Wilcox. 1985. Effects of climatic and management factors on conception rate of dairy cattle in subtropical environments. J. Dairy Sci. 68:78-85.

Cassell, B. G., S. M. Jobst, M. L. McGuillard, and R. E. Pearson. 2002. Evaluating sire selection practices using lifetime net income functions. J. Dairy Sci. 85:3492-3498.

de Vries, A., R. Giesy, L. Ely, A. de Araujo, A. Andreasen, B. Broaddus, S. Eubanks, D. Mayo, P. Miller, T. Seawright, and C. Vann. 2003. Dairy Business Analysis Project: 2001 Financial Summary. Ext. Publ. AN136. Univ. Florida, Gainesville. Online. Available http:// edis.ifas.ufl.edu/AN136. Accessed July 24, 2004.

Dohoo, I., W. Martin, and H. Stryhn. 2003. Veterinary Epidemiologic Research. AVC Inc., Charlottetown, PEI, Canada.

Ducrocq, V., and J. Sölkner. 1994. The Survival Kit - a Fortran package for the analysis of survival data. Vol. 22. Pages 51-52 in Proc. 5th World Congr. Genet. Appl. to Livest. Prod., Guelph, ON, Canada.

Ferguson, J. D., and D. T. Galligan. 1999. Veterinary Reproductive Programs. Pages 131-137 in Proc. 32nd Annu. Meet. Am. Assoc. Bovine Pract., Nashville, TN.

Littell, R. C., P. R. Henry, and C. B. Ammerman. 1998. Statistical analysis of repeated measures data using SAS procedures. J. Anim. Sci. 76:1217-1231.

Littell, R. C., G. A. Milliken, W. W. Stroup, and R. D. Wolfinger. 1996. SAS System for Mixed Models. SAS Institute, Cary, NC.
National Animal Health Monitoring System. 2002. Part 1: Reference of dairy health and management in the United States. Ctr. Epidemiol. Anim. Health, Fort Collins, CO.

Niles, D., C. A. Risco, and M. J. Thatcher. 2002. Seasonal evaluation of artificial insemination and natural service pregnancy rates in dairy herds. Compend. Contin. Educ. Prac. Vet. 24:S44-S48.

Oseni, S., I. Misztal, S. Tsuruta, and R. Rekaya. 2003. Seasonality of days open in US Holsteins. J. Dairy Sci. 86:3718-3725.

Ott, R. S. 1986. Breeding soundness examination in bulls. Pages 125 136 in Current Therapy of Theriogenology. 2nd ed., D. A. Morrow, ed. W. B. Saunders Co., Philadelphia, PA.

Pecsok, S. R., M. L. McGilliard, and R. L. Nebel. 1994. Conception rates: Derivation and estimates for effects of estrus detection on cow profitability. J. Dairy Sci. 77:3008-3015.

Plaizier, J. C. B., G. J. King, J. C. M. Dekkers, and K. Lissemore. 1998. Modeling the relationship between reproductive performance and net-revenue in dairy herds. Agric. Sys. 56:305-322.

Risco, C. A., F. Moreira, M. DeLorenzo, and W. W. Thatcher. 1998. Timed artificial insemination in dairy cattle - Part II. Compend. Contin. Educ. Prac. Vet. 20:1284-1289.

Smith, J. W., L. O. Ely, W. D. Gilson, and W. M. Graves. 2004. Effects of artificial insemination vs. natural service breeding on production and reproduction parameters in dairy herds. Prof. Anim. Sci. 20:185-190.

VanRaden, P. M., A. H. Sanders, M. E. Tooker, R. H. Miller, H. D. Norman, M. T. Kuhn, and G. R. Wiggans. 2004. Development of a national genetic evaluation for cow fertility. J. Dairy Sci. 87:2285-2292.

Washburn, S. P., W. J. Silvia, C. H. Brown, B. T. McDaniel, and A. J. McAllister. 2002. Trends in reproductive performance in Southeastern Holstein and Jersey DHI herds. J. Dairy Sci. 85:244-251.

Williamson, N. B., R. S. Morris, and G. A. Anderson. 1978. Pregnancy rates and nonreturn rates following artificial and natural breeding in dairy herds. Aust. Vet. J. 54:111-120. 